(c) American Dairy Science Association, 2004.

\title{
Measurement of Bovine IgG by Indirect Competitive ELISA as a Means of Detecting Milk Adulteration
}

\author{
I. P. Hurley, R. C. Coleman, H. E. Ireland, and J. H. H. Williams \\ Chester Centre for Stress Research, Department of Biological Sciences, \\ University College Chester, Parkgate Road, Chester, CH1 4BJ, UK
}

\begin{abstract}
The aim of this work was to develop an assay capable of detecting adulteration of high premium milk with milk from cheaper sources. An indirect, competitive ELISA was developed for the rapid detection of cows' milk in the milk of goat, sheep, and buffalo. The assay uses a monoclonal antibody produced against bovine IgG. This antibody recognizes a species-specific epitope on the heavy chain of both bovine $\operatorname{IgG}_{1}$ and $\operatorname{IgG}_{2}$. A peroxidase-conjugated anti-mouse IgG antibody was used to detect bound monoclonal antibody and subsequent enzymatic conversion of substrate resulted in clear differences in absorbance when assaying different mixtures of milks adulterated with cows' milk. Once optimized, the ELISA was found to be highly specific. Detection limits of the assay are $1.0 \mu \mathrm{g} / \mathrm{mL}$ of bovine IgG, or $0.1 \%$ (vol/vol) adulteration with cows' milk. The assay was highly reproducible $(\mathrm{CV}<10 \%)$ and performed equally well when used to detect bovine IgG in mixtures with the 3 types of milk tested.

The ELISA performance makes it suitable for development as a kit, for use in the field as a high throughput screening ELISA.
\end{abstract}

(Key words: milk adulteration, ELISA, IgG)

\section{INTRODUCTION}

Dairy products are diverse and are important commercially within the food industry. The products that use milk include bottled milk, butter, cheese, and yogurt. The milk used to make such products is obtained from a number of species including cow, sheep, goat, and buffalo. European laws require food manufacturers to state the species of origin of the milk used for cheese production or other dairy products. For example, buffalo mozzarella cheese cannot be labeled and sold as such unless it has been produced from milk that is $100 \%$ buffalo (European Commission, 2001).

Received August 29, 2003.

Accepted October 7, 2003.

Corresponding author: J. H. H. Williams; e-mail: john.williams @chester.ac.uk.
There are 2 main reasons why the detection of milk adulteration is important to the consumer. The first is the fraudulent practice of blending more expensive milk with cow's milk to reduce production costs and increase profit margins (Maudet and Taberlet, 2001). The second is to protect consumers who do not wish to ingest milk from certain species. A proportion of the population have intolerance or are allergic to milk from certain species (Halken, 2003; Sampson, 2003). Milk from certain species may also be avoided for religious, ethical, or cultural reasons (Shatenstein and Ghadirian, 1998). It is therefore important to protect the consumer by ensuring that adequate control measures are in place and that the food analyst has suitable methods for the detection of fraudulent milk adulteration.

The problem of authentication in the food industry is not limited to milk and milk products. Food product adulteration problems have been addressed with regard to meat and fish, with several analytical approaches being adopted over the past few years. Assays developed for detection of speciation in meat and fish have included ELISA, PCR, infrared spectroscopy, mass spectroscopy, NMR, and agar-gel immunodiffusion (Carrera et al., 1997; Dennis, 1998; Asensio et al., 2001; Herman, 2001; Skarpeid et al., 2001).

Numerous methods have been developed for the detection of species origin in milk products (Rodriguez et al., 1991; Ding and Xu, 2000; Bania et al., 2001; Bottero et al., 2002). Nonimmunological methods have focused on PAGE or isoelectrofocusing of milk $\mathrm{CN}$ or whey proteins (Amigo et al., 1992; Levieux and Venien, 1994; Malin et al., 1994). The EC reference method is based on isoelectric focusing of $\gamma-\mathrm{CN}$, and sets a detection limit of $1 \%$ (vol/vol) cow's milk (European Commission, 2001).

Polymerase chain reaction of DNA extracted from somatic cells from milk has been successfully applied to detect adulteration of milk products (Plath et al., 1997; Bania et al., 2001; Klotz and Einspanier, 2001; Maudet and Taberlet, 2001; Rea et al., 2001; Bottero et al., 2002). However, PCR is usually only reliable for qualitative analysis.

Immunological methods have been employed extensively in food analysis (Williams et al., 1996; Bonwick et al., 2003). Most of the immunological methods currently 
available for the detection of adulteration in milk use polyclonal antisera against milk proteins and their different types: $\beta$-CN, $\gamma$-CN, $\beta$-lactoglobulins, or other whey proteins (Levieux and Venien, 1994; Anguita et al., 1996; Haza et al., 1999), despite the problems of distinguishing between milk proteins of closely related species, such as buffalo and cow. Another protein found in milk, IgG, has been used successfully as a target antigen in a simple ELISA based on an immunoblotting procedure (Inda et al., 1998). In addition a number of commercial ELISA have been produced for the detection of adulteration of other species milk by cow's milk such as r-Biopharm Bovine Casein Kit (cat. no. R5102), and Tepnel Biokits Bovine Casein Kit (cat. no. 902062W). However, these methods are unable to distinguish between cow's milk and buffalo milk.

The aim of this study was to develop a method for the detection of cow's milk in other milks. The approach was to use an indirect competitive ELISA for the detection of bovine IgG in adulterated milk samples, and to detect and quantify defined amounts of cow's milk that have been used to adulterate sheep, goat, and buffalo milk.

\section{MATERIALS AND METHODS}

\section{Preparation and Source of Materials}

All reagents were obtained from Sigma Chemical Co. Ltd. (Poole, Dorset, UK) unless otherwise specified. Authenticated raw cow, sheep, goat, and buffalo milk was obtained fresh from local farms. Fresh milk was immediately frozen and stored at $-20^{\circ} \mathrm{C}$ until needed. Prior to use the milk was either defrosted overnight at $4^{\circ} \mathrm{C}$, or defrosted in a water bath at $37^{\circ} \mathrm{C}$. On defrosting, milk samples were agitated.

Stock antigen solution was prepared by lyophilizing bovine IgG (Sigma I-5506) in phosphate buffered saline (PBS: NaCl, $140 \mathrm{~m} M$; KCl, $3 \mathrm{mM} ; \mathrm{Na}_{2} \mathrm{HPO}_{4}, 2 \mathrm{~m} M$; $\left.\mathrm{KHPO}_{4}, 10 \mathrm{~m} M: \mathrm{pH} 7.2\right)$. Aliquots $(100 \mu \mathrm{L})$ were stored at $-20^{\circ} \mathrm{C}$ until required.

\section{Indirect Noncompetitive ELISA}

Immunolon 4BX ELISA plates (Thermo Life Sceinces, Basingstoke, UK) were coated overnight at $4^{\circ} \mathrm{C}$ with $100 \mu \mathrm{L} /$ well bovine IgG in PBS. The plates were blocked for $1 \mathrm{~h}$ at $37^{\circ} \mathrm{C}$ with $250 \mu \mathrm{L} /$ well PBS plus $3 \%$ (wt/vol) dried nonfat milk powder (Safeway brand, UK) before being washed 3 times with wash buffer (PBS with $0.05 \%$ Tween 20 ). A $100 \mu \mathrm{L} /$ well volume of monoclonal anti-bovine IgG antibody ( $\operatorname{IgG}_{1}$, Sigma B6901), diluted 1/16,000 with ELISA buffer was added to the plate and incubated for $1 \mathrm{~h}$ at $25^{\circ} \mathrm{C}$. The wells of the plate were then washed 3 times with wash buffer, before being incubated with $100 \mu \mathrm{L} /$ well goat anti-mouse IgG polyvalent horseradish peroxidase conjugate (Sigma 0412), diluted $1 / 1000$ in wash buffer with $3 \%$ (wt/vol) dried nonfat milk powder. After being washed 3 times with wash buffer, the plate was then incubated with $100 \mu \mathrm{L} /$ well of the tetramethyl benzidine (TMB) substrate, for $1 \mathrm{~h}$ at $25^{\circ} \mathrm{C}$. The reaction was stopped by addition of $50 \mu \mathrm{L} /$ well of $1 M$ phosphoric acid, and the absorbance was measured at $450 \mathrm{~nm}$ on a microplate reader (Dynatech MR700).

\section{Indirect Competitive ELISA}

The assay was performed as above until the addition of monoclonal anti-bovine IgG antibody. At this step bovine IgG or milk sample were added as competitor.

\section{Estimation of Percentage Adulteration by Bovine Milk by Analysis of Unknown Samples}

A series of standards with varied cow's milk adulteration (ranging from 0.5 to $10 \%$ ) were prepared by one operator for each of sheep, goat, and buffalo milk. These unknowns were run in assays alongside adulteration standards by another operator in a series of blind trials. All samples and standards were tested in triplicate.

\section{RESULTS}

A checkerboard titration was performed to determine the optimal plate coating (bovine IgG) concentration and the primary antibody (anti-bovine IgG) dilution. Absorbances were still high at low concentrations of primary antibody $(1 / 128,000)$, indicating a high specificity for the monoclonal anti-bovine IgG antibody (Figure 1). Based on the results a plate coating concentration of $5 \mu \mathrm{g} / \mathrm{mL}$ and primary antibody dilution of $1 /$ 16,000 were chosen for the assay. Secondary antibody (anti-mouse IgG peroxidase conjugate) dilution was optimized using an indirect competitive ELISA. A differential of $0.8 \mathrm{AU}$ was maintained at secondary antibody dilution of 1/2000 (Figure 2). Based on these data the optimized ELISA conditions were: plate coating, $5 \mu \mathrm{g} /$ $\mathrm{mL}$; primary antibody, 1/16,000 dilution; secondary antibody, 1/2000 dilution.

The addition of bovine IgG to the competitive ELISA caused inhibition of antibody binding (Figure 3). The assay had a working range of 1 to $100 \mu \mathrm{g} / \mathrm{mL}$, a detection limit for IgG of $1 \mu \mathrm{g} / \mathrm{mL}$, and 50\% inhibition (IC50) of $8 \mu \mathrm{g} / \mathrm{mL}$ bovine IgG (Figure 3). Addition of cows' milk also caused inhibition of signal in the competitive ELISA (Figure 4). The assay had a working range of 1/ 2000 to $1 / 50$ dilution of cow's milk, a detection limit of $1 / 2000$ and an IC50 value of 1/100 (Figure 4). 


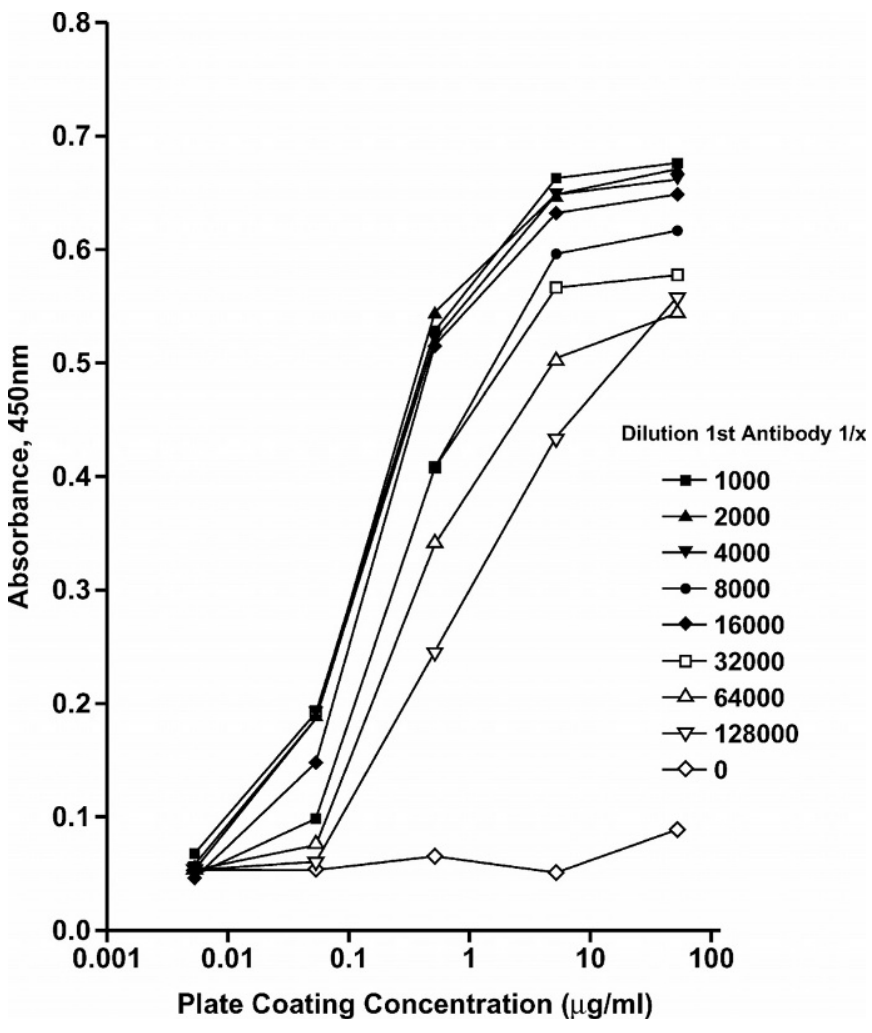

Figure 1. Optimization of plate coating and primary antibody dilution in an indirect noncompetitive checkerboard ELISA. Plates were coated with variable dilutions of bovine IgG. Dilutions of antibodies were: primary antibody - anti-bovine IgG, variable; secondary antibody - anti-mouse IgG horseradish peroxidase conjugate, 1/1000.

The specificity of the assay was determined by testing how the assay performed with cows' milk, goats' milk, sheeps' milk or buffalos' milk acting as the competitor for the monoclonal anti-bovine IgG antibody (Figure 5). Only cows' milk caused any inhibition of antibody binding to the plate antigen (Figure 5). There was no inhibition of signal by milk from goat, sheep, and buffalo even when tested at $1 / 2$ dilution (Figure 5 ). The results indicated that the monoclonal antibody exhibits no cross-reactivity with goat, sheep or buffalo IgG, and was considered to be specific for bovine IgG. The assay was also tested using various types of treated cows' milks and soymilk. Fresh untreated cow's milk and fresh pasteurized cow's milk both produced similar inhibition curves (Figure 6), indicating that the specificity of the antibody for bovine IgG is not altered by the pasteurization process. Ultra-high temperature and reconstituted dried milk caused no inhibition of the antibody (Figure 6), suggesting that severe heat treatment causes denaturation of the milk IgG. Soymilk did not cause any inhibition of the antibody binding to the plate antigen (Figure 6).

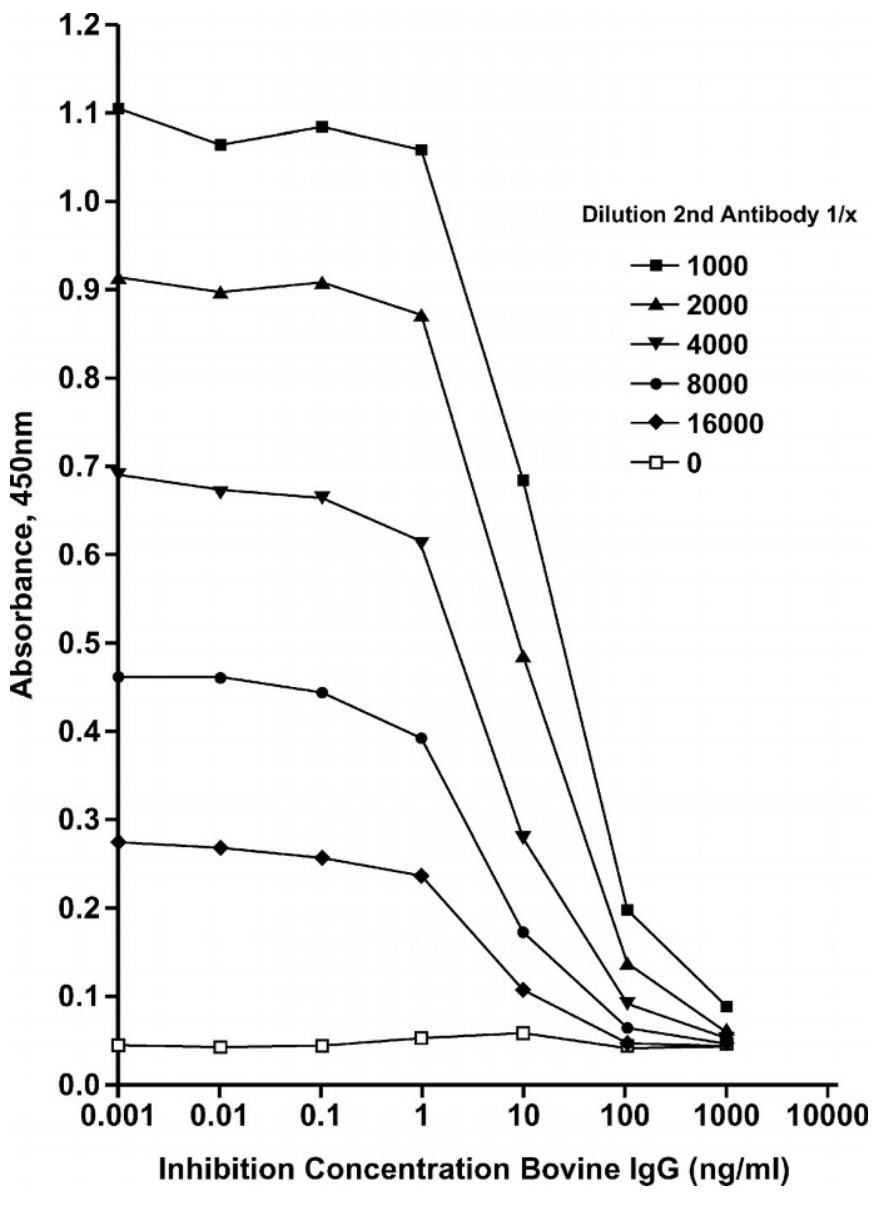

Figure 2. Optimization of inhibitor concentration and secondary antibody dilution in an indirect competitive checkerboard ELISA. Plates were coated with $5 \mu \mathrm{g} / \mathrm{mL}$ bovine IgG. Dilutions of antibodies were: primary antibody - anti-bovine IgG, 1/16,000; secondary antibody - anti-mouse IgG horseradish peroxidase conjugate, variable.

The ability of the ELISA to detect bovine IgG in adulterated milk samples was tested by spiking milk from goat, sheep, and buffalo with cow's milk using a range of adulteration percentages. The assay successfully detected $0.1 \%$ adulteration by cow's milk in all the milks tested (Figure 7). Reproducible inhibition curves were obtained for cow's milk adulteration of goat, sheep, and buffalo milk (Figure 7). These adulteration standards were then used in a simple blind trial in which the assay's estimation of adulteration by cow's milk could be tested against adulterated samples (ranging from 0.5 to $10 \%$ ) prepared independently in the laboratory. In each species the ELISA was able to detect adulteration down to $0.5 \%$ and by Wilcoxon signed rank test there was no difference between the known and estimated values (cow in sheep, $P=0.125$; cow in goat, $P=$ 0.188; cow in buffalo, $P=0.063$ ). 


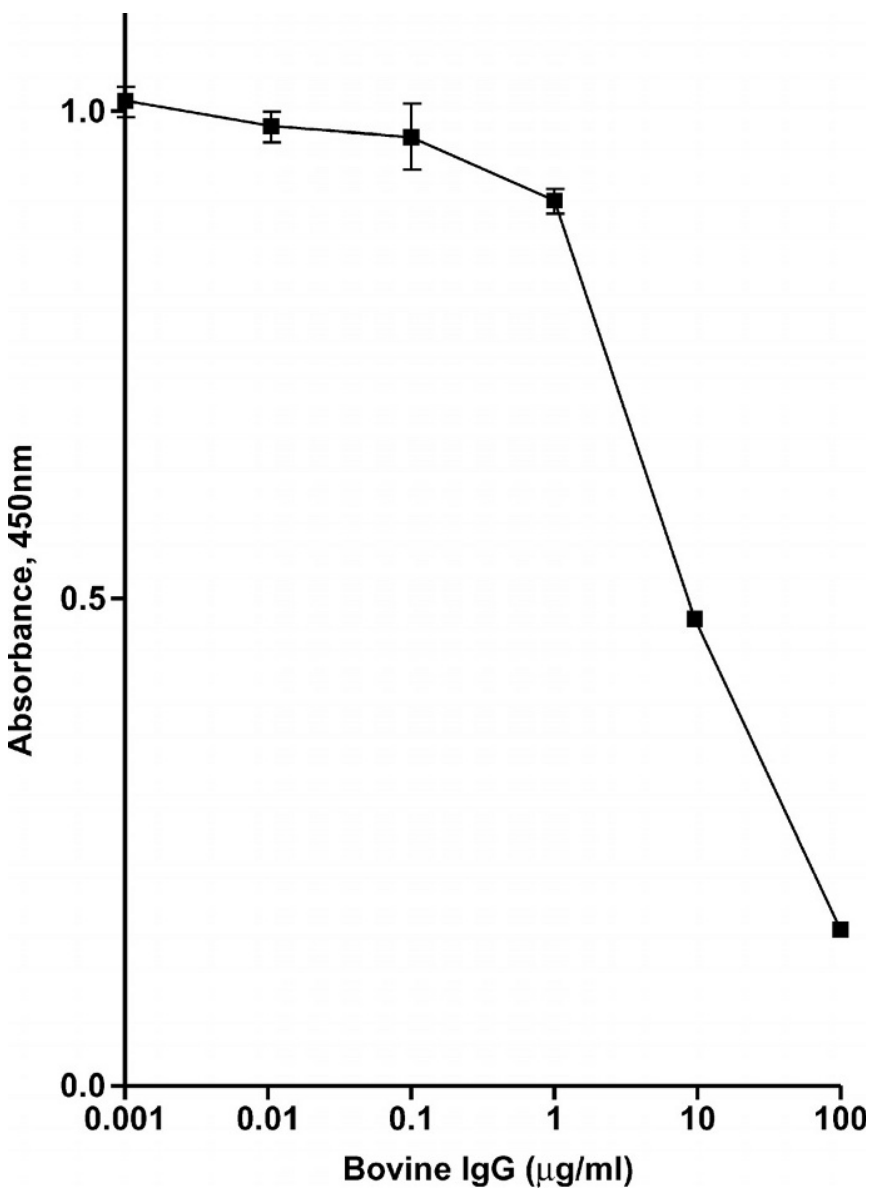

Figure 3. Standard curve for the optimized indirect competitive ELISA for bovine IgG. Plates were coated with $5.0 \mu \mathrm{g} / \mathrm{mL}$ bovine IgG. Dilutions of antibodies were: primary antibody - anti-bovine IgG, 1/ 16,000; secondary antibody - anti-mouse IgG horseradish peroxidase conjugate, $1 / 2000$. Data points are means \pm standard deviation, $\mathrm{n}=3$.

\section{DISCUSSION}

An indirect competitive ELISA was developed for the detection of cows' milk in other species' milk, which is both sensitive and specific. When developing an optimized ELISA assay for the detection of adulteration of goat, sheep, or buffalo milk by cows' milk, the target antigen and antibody used must be selected carefully. Previous attempts to develop immunoassays to detect adulteration by cows' milk have focused on milk proteins such as caseins or whey proteins (Anguita et al., 1996; Richter et al., 1997). However, these targets are prone to proteolysis and caseins are often poor immunogens (Levieux and Venien, 1994). Because there is similarity between the primary sequences of caseins, many assays also show a poor ability to distinguish between milk of closely related species e.g., cow and buffalo; sheep and goat (Bottero et al., 2002).

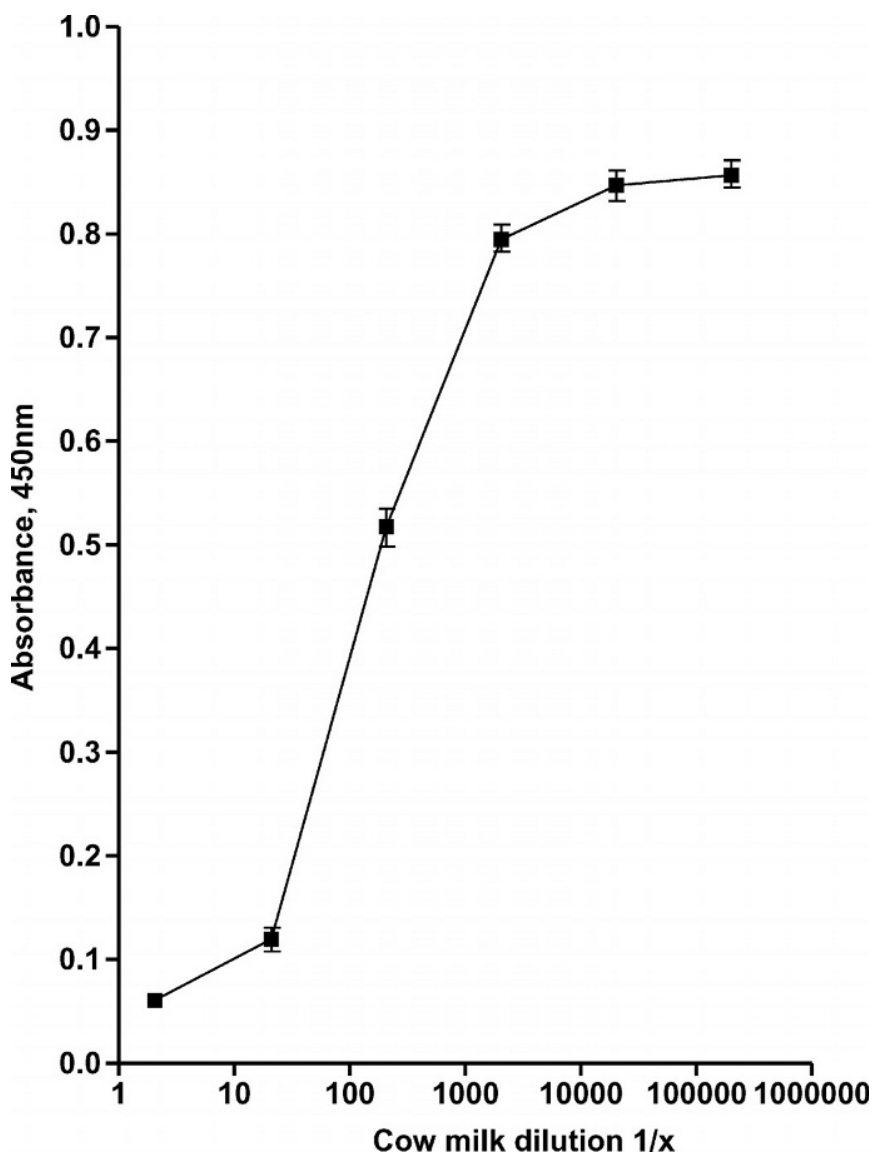

Figure 4. Standard curve of cow's milk in the optimized indirect competitive ELISA for bovine IgG. Plates were coated with $5.0 \mu \mathrm{g} /$ $\mathrm{mL}$ bovine IgG. Dilutions of antibodies were: primary antibody anti-bovine IgG, 1/16,000; secondary antibody - anti-mouse IgG horseradish peroxidase conjugate, 1/2000. Data points are means \pm standard deviation, $\mathrm{n}=3$.

Immunoglobin $\mathrm{G}$ is highly immunogenic, and this study suggests that it is a suitable target antigen for use in milk speciation. The specificity and sensitivity of any ELISA assay is determined by the antisera used in the assay. The monoclonal anti-bovine IgG used in this study is both highly specific, highly sensitive and is readily available. The antibody is highly specific for bovine IgG. The ELISA detection limit of $1 \mu \mathrm{g} / \mathrm{mL}$ bovine IgG demonstrates the high sensitivity of the assay, with no significant cross-reactivity with ovine, caprine, or buffalo IgG. The assay is equally sensitive when tested with pasteurized cows' milk, untreated milk and milk that has been previously frozen (data not shown). However, the assay is unable to detect bovine IgG in UHT or reconstituted nonfat dried milk, as presumably the heat treatment required to produce such products results in the denaturation of the target epitope. In theory, the ELISA would be unable to detect adulteration of other species' milk by UHT or dried cows' milk. 


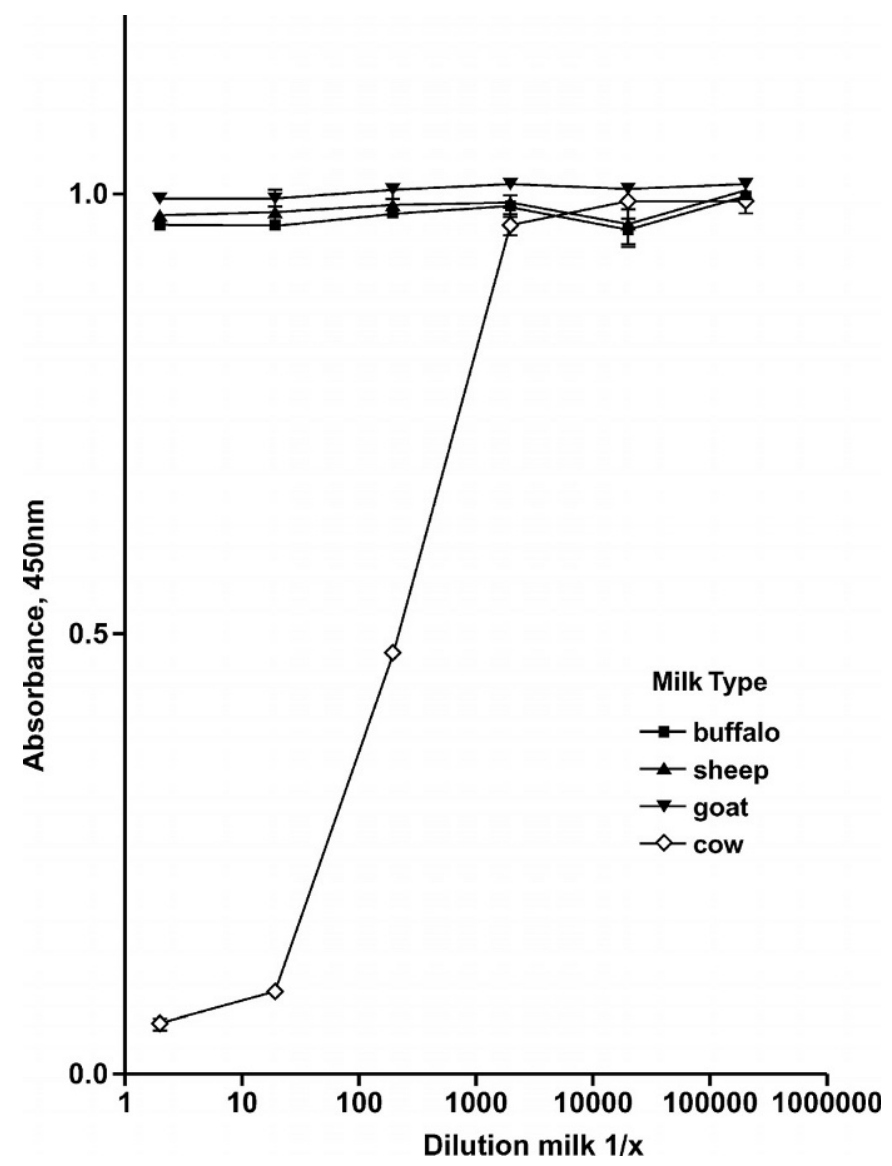

Figure 5. Titration of various milks in an indirect competitive ELISA for bovine IgG. Plates were coated with $5.0 \mu \mathrm{g} / \mathrm{mL}$ bovine IgG. Dilutions of antibodies were: primary antibody - anti-bovine IgG, 1/ 16,000; secondary antibody - anti-mouse IgG horseradish peroxidase conjugate, $1 / 2000$.

However, it is possible that the cost of these treated milk products would make their use in adulteration unprofitable. However, the problem could be addressed by the production of antibodies specific for the heatdenatured epitopes.

This study showed that the assay could detect cows' milk in goat, sheep, or buffalo milk with a detection limit for all milks of $0.1 \%$. Since, at present, the reference method for the detection of cows' milk in sheep milk is 1\% (European Commission, 2001), this detection limit is more than adequate for current authenticity controls and field screenings. In blind trials $0.5 \%$ adulteration with cows' milk, vol/vol, was successfully detected. The assay can be said to be particularly useful when used for screening buffalo milk for authenticity.

The monoclonal antibody used for the IC-ELISA is currently being exploited in the development of an antibovine IgG sandwich assay that could be more sensitive. The assay uses a commercially available polyclonal

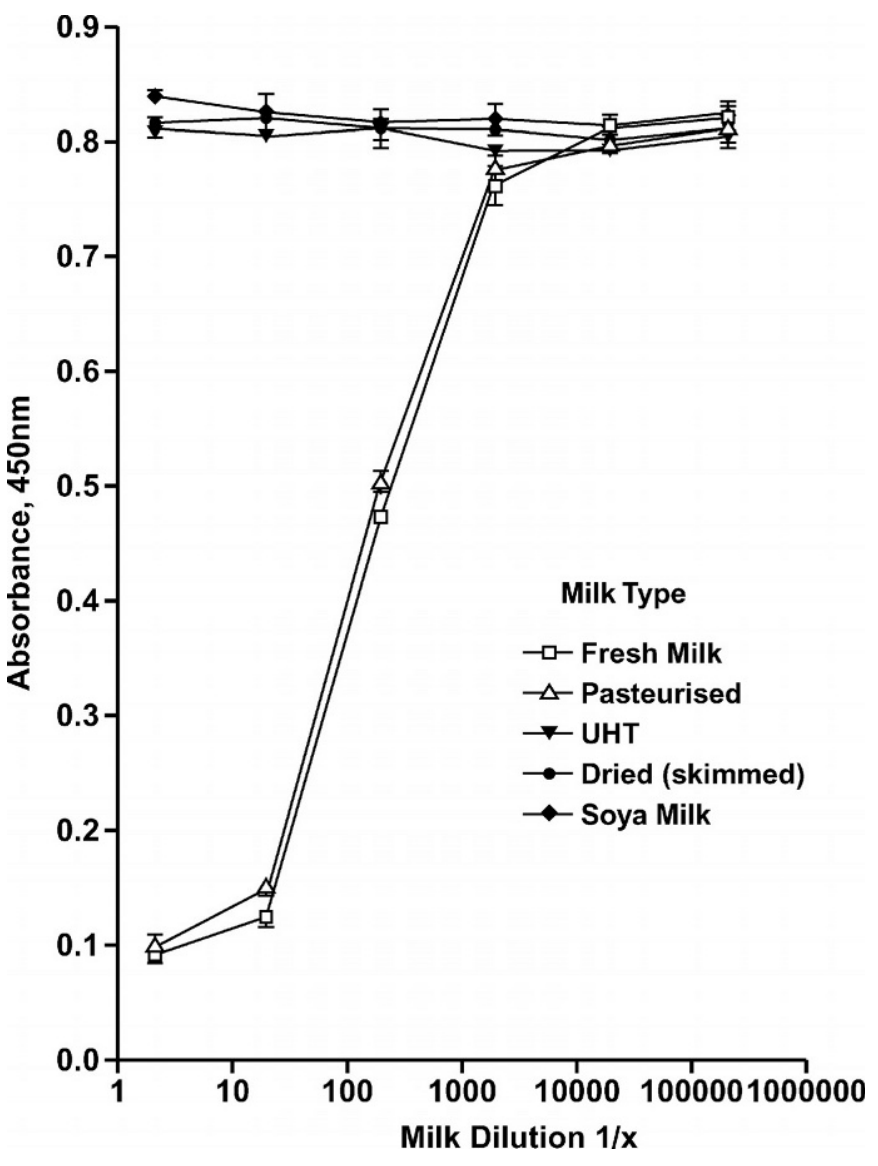

Figure 6. Detection of cow's milk in adulterated samples of sheep, goat, and buffalo milk using the optimized indirect competitive ELISA for bovine IgG. Plates were coated with $5.0 \mu \mathrm{g} / \mathrm{mL}$ bovine IgG. Dilutions of antibodies were: primary antibody - anti-bovine IgG, 1/ 16,000; secondary antibody: anti-mouse IgG horseradish peroxidase conjugate, $1 / 2000$. Data points are means \pm standard deviation, $\mathrm{n}=3$.

anti-bovine IgG antibody as the capture antibody. Further work is also underway to develop both of these assays for use in the detection of adulteration by bovine milk of goat, sheep, and buffalo cheese, an area that is currently being explored using both immunological and DNA-based methods (Richter et al., 1997; Klotz and Einspanier, 2001; Maudet and Taberlet, 2001; Rea et al., 2001; Bottero et al., 2002). The DNA-based methods involve the development of PCR techniques for the detection of bovine or caprine genes from somatic cells derived from cow or goat milk, and may have an advantage over ELISA techniques in higher sensitivity and rapid performance (Klotz and Einspanier, 2001). However, for routine authenticity control and food standards enforcement, ELISA has the advantage over PCR of being quantitative; not only can adulteration by cow's milk be detected, it can be quantified, an attractive quality when an assay is being considered for use in routine analysis of dairy products. 


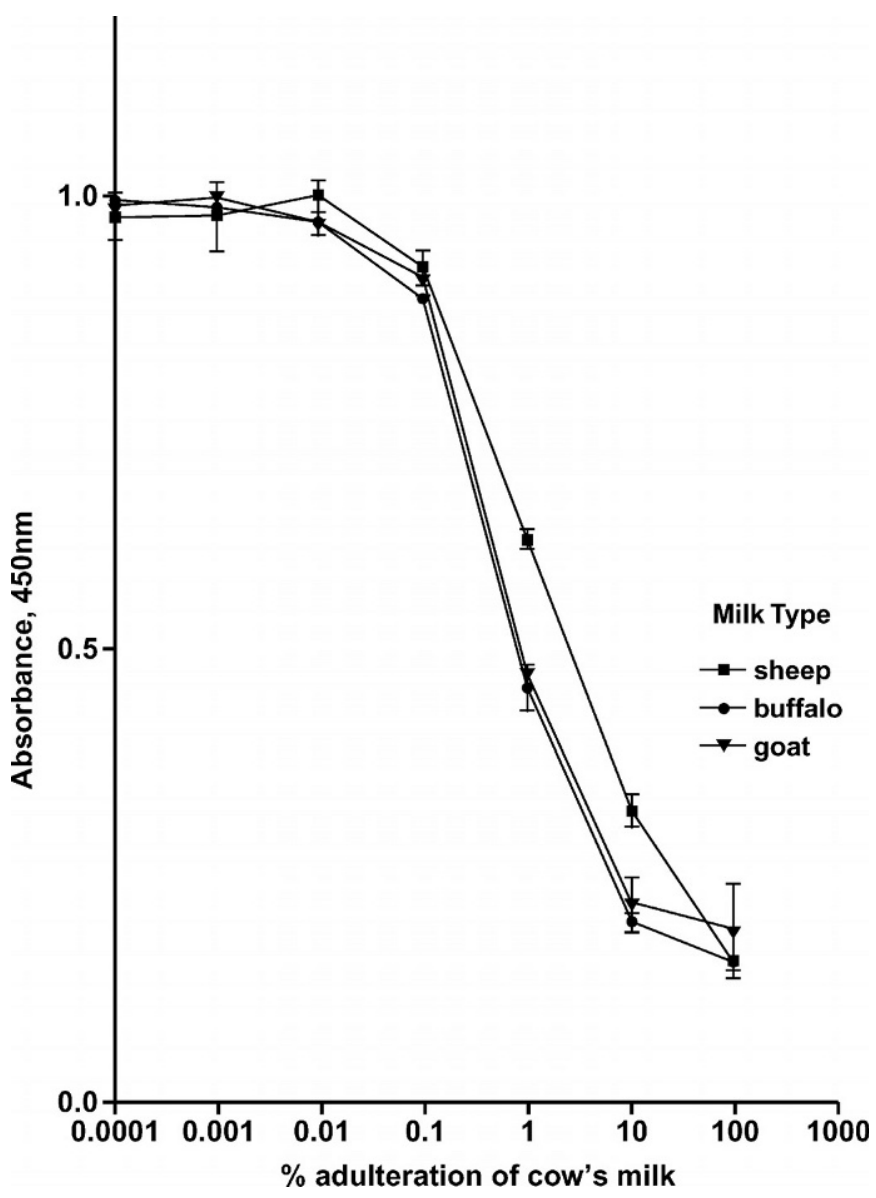

Figure 7. Performance of optimized indirect competitive ELISA for bovine IgG using various types of treated milk as inhibitors. Plates were coated with $5.0 \mu \mathrm{g} / \mathrm{mL}$ bovine IgG. Dilutions of antibodies were: primary antibody - anti-bovine IgG, 1/16,000; secondary antibody anti-mouse IgG horseradish peroxidase conjugate, 1/2000. Data points are means \pm standard deviation, $\mathrm{n}=3$.

\section{ACKNOWLEDGMENTS}

This study (Q01045) was funded by the Food Authenticity and Surveillance Programme of the UK Food Standards Agency. Fresh milk was provided by Aelwyn Owen (Tyddyn Eli, Llangwm) and Berwyn and Hywel Hughes (Ystrad Fawr, Llangwm).

Contribution of the authors: IPH (experimental design, practical work and analysis); RCC (experimental design and practical work); HEI (experimental design and practical work); JHHW (conception of study and experimental design). IPH and JHHW planned the article and IPH produced the first draft. All authors were involved in revisions and approved the final version of the manuscript.

\section{REFERENCES}

Amigo, L., M. Ramos, L. Calhau, and M. Barbosa. 1992. Comparison of electrophoresis, isoelectric-focusing, and immunodiffusion in determinations of cows and goats milk in Serra-Da-Estrela cheeses. Lait 72:95-101.

Anguita, G., R. Martin, T. Garcia, P. Morales, A. I. Haza, I. Gonzalez, B. Sanz, and P. E. Hernandez. 1996. Immunostick ELISA for detection of cow's milk in ewe's milk and cheese using a monoclonal antibody against bovine beta-casein. J. Food Prot. 59:436-437.

Asensio, L., I. Gonzalez, A. Fernandez, A. Cespedes, M. A. Rodriguez, P. E. Hernandez, T. Garcia, and R. Martin. 2001. Identification of nile perch (Lates niloticus), grouper (Epinephelus guaza), and wreck fish (Polyprion americanus) fillets by PCR amplification of the 5S rDNA gene. J. AOAC Int. 84:777-781.

Bania, J., M. Ugorski, A. Polanowski, and E. Adamczyk. 2001. Application of polymerase chain reaction for detection of goats' milk adulteration by milk of cow. J. Dairy Res. 68:333-336.

Bonwick, G. A., C. J. Smith, and J. H. H. Williams. 2003. Immunoassays for food safety and quality. Food Sci. Technol. 17:32-34.

Bottero, M. T., T. Civera, A. Anastasio, R. M. Turi, and S. Rosati. 2002. Identification of cow's milk in "buffalo" cheese by duplex polymerase chain reaction. J. Food Prot. 65:362-366.

Carrera, E., T. Garcia, A. Cespedes, I. Gonzalez, B. Sanz, P. E. Hernandez, and R. Martin. 1997. Immunostick colorimetric ELISA assay for the identification of smoked salmon, trout and bream. J. Sci. Food Agric. 74:547-550.

Dennis, M. J. 1998. Recent developments in food authentication. Analyst 123:151R-156R.

Ding, H. B., and R. J. Xu. 2000. Near-infrared spectroscopic technique for detection of beef hamburger adulteration. J. Agric. Food Chem. 48(6):2193-2198

EuropeanCommission. 2001. EC 213/2001 Methods for the analysis and quality evaluation of milk and milk products. Off. J. Eur. Comm. 44:L37/31-L37/99.

Halken, S. 2003. Early sensitisation and development of allergic airway disease-risk factors and predictors. Paediatr. Respir. Rev. 4:128-134.

Haza, A. I., P. Morales, R. Martin, T. Garcia, G. Anguita, B. Sanz, and P. E. Hernandez. 1999. Detection and quantification of goat's cheese in ewe's cheese using a monoclonal antibody and two ELISA formats. J. Sci. Food Agric. 79:1043-1047.

Herman, L. 2001. Determination of the animal origin of raw food by species-specific PCR. J. Dairy Res. 68:429-436.

Inda, L. A., P. Razquin, F. Lampreave, M. A. Alava, and M. Calvo. 1998. Rapid, sensitive, enzyme-immunodotting assay for detecting cow milk adulteration in sheep milk-A modern laboratory project. J. Chem. Educ. 75:1618-1621.

Klotz, A., and R. Einspanier. 2001. Development of a DNA-based screening method to detect cow milk in ewe, goat and buffalo milk and dairy products using PCR-LCR- EIA-technique. Milchwiss.Milk Sci. Int. 56:67-70.

Levieux, D., and A. Venien. 1994. Rapid, Sensitive 2-Site Elisa for Detection of Cows Milk in Goats or Ewes Milk Using MonoclonalAntibodies. J. Dairy Res. 61:91-99.

Malin, E. L., J. J. Basch, J. J. Shieh, B. C. Sullivan, and V. H. Holsinger. 1994. Detection of adulteration of buttermilk powder by gel-electrophoresis. J. Dairy Sci. 77:2199-2206.

Maudet, C., and P. Taberlet. 2001. Detection of cows' milk in goats' cheeses inferred from mitochondrial DNA polymorphism. J. Dairy Res. 68:229-235.

Plath, A., I. Krause, and R. Einspanier. 1997. Species identification in dairy products by three different DNA-based techniques. Z. Lebensm-Unters-Forsch. A-Food Res. Technol. 205:437-441.

Rea, S., K. Chikuni, R. Branciari, R. S. Sangamayya, D. Ranucci, and P. Avellini. 2001. Use of duplex polymerase chain reaction (duplex-PCR) technique to identify bovine and water buffalo milk used in making mozzarella cheese. J. Dairy Res. 68:689-698.

Richter, W., I. Krause, C. Graf, I. Sperrer, C. Schwarzer, and H. Klostermeyer. 1997. An indirect competitive ELISA for the detection of cows' milk and caseinate in goats' and ewes' milk and cheese using polyclonal antibodies against bovine gamma-ca- 
seins. Z. Lebensm-Unters-Forsch. A-Food Res. Technol. 204(1):21-26.

Rodriguez, E., R. Martin, T. Garcia, J. I. Azcona, B. Sanz, and P. E. Hernandez. 1991. Indirect Elisa for Detection of Goats Milk in Ewes Milk and Cheese. Int. J. Food Sci. Technol. 26(5):457-465. Sampson, H. A. 2003. Food allergy. J. Allergy Clin. Immunol. 111:S540-S547.

Shatenstein, B., and P. Ghadirian. 1998. Influences on diet, health behaviours and their outcome in select ethnocultural and religious groups. Nutrition 14:223-230.
Skarpeid, H.-J., R. E. Moe, and U. G. Indahl. 2001. Detection of mechanically recovered meat and head meat from cattle in ground beef mixtures by multivariate analysis of isoelectric focusing protein profiles. Meat Sci. 57:227-234.

Williams, J. H. H., A. L. Tyreman, D. J. Deeble, M. Jones, C. J. Smith, J. F. Christiansen, and P. C. Beaumont. 1996. Immunological detection of modified DNA bases in irradiated food. Pages 367374 in Detection Methods for Irradiated Food: Current Status. C. H. McMurray, E. M. Stewart, R. Gray, and J. Pearce, eds. Royal Soci. Chem., Cambridge, UK. 